\title{
A review of evidence linking ventilation rates in dwellings and respiratory health: a focus on house dust mites and mould
}

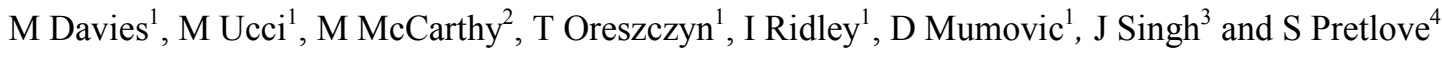 \\ ${ }^{1}$ Bartlett School of Graduate Studies, University College London. \\ ${ }^{2}$ Department of Epidemiology \& Public Health, University College London \\ ${ }^{3}$ Environmental Building Solutions Ltd. \\ ${ }^{4}$ London South Bank University
}

\begin{abstract}
This paper reviews the literature for evidence of links between ventilation rates in dwellings and moisture related respiratory health with a particular focus on house dust mites (HDM) and fungal growth. There is general consensus that a link exists between ventilation rates in dwellings and respiratory hazards (for example HDM). There is also general consensus of a link between these respiratory hazards and respiratory problems, but it is not clear to what extent hazards cause ill-health. Most existing data are inadequate for conclusions to be drawn whether ventilation rates directly cause respiratory problems. We discuss the many difficulties in attempting to establish these relationships, and suggest the need for larger studies.
\end{abstract}

Key words: review, ventilation rates, respiratory health, house dust mites, mould.

\section{Introduction}

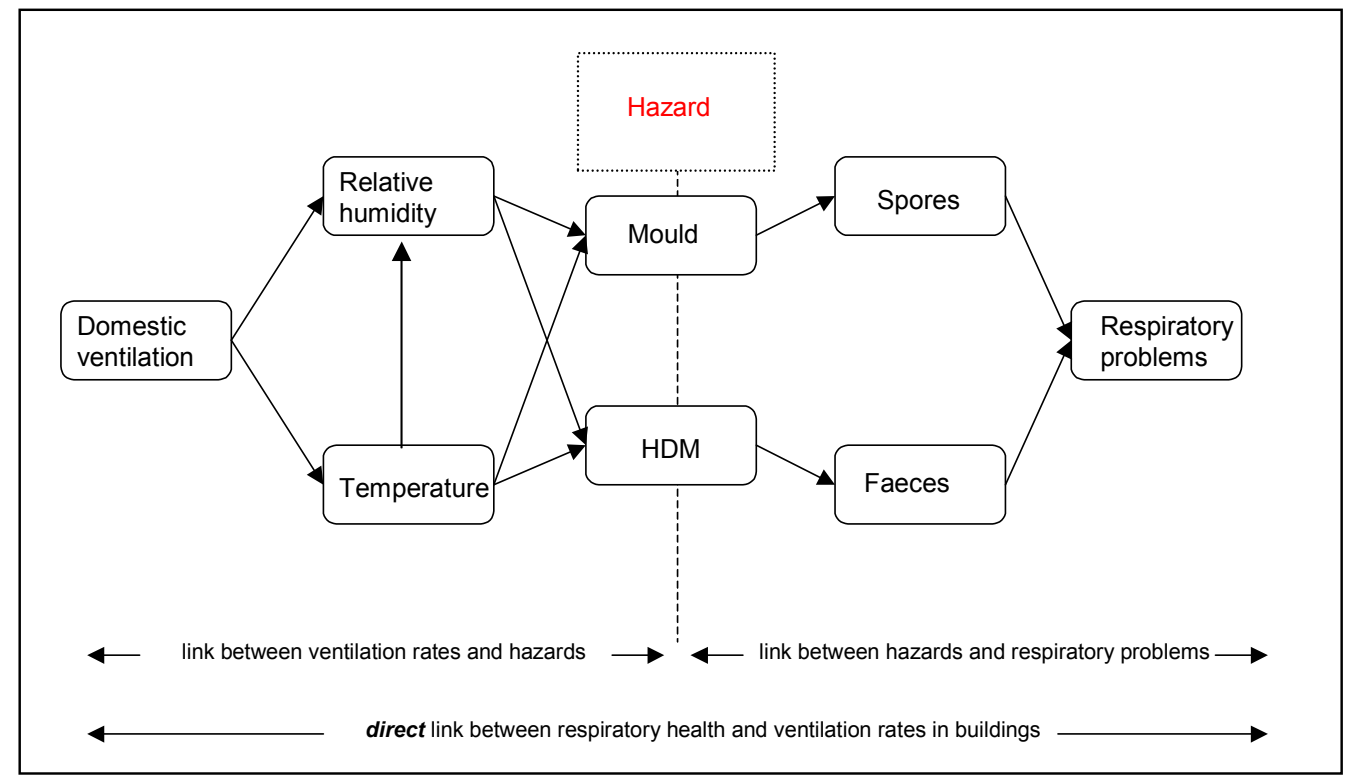

Figure 1. Postulated pathways between ventilation and related respiratory problems

This review focuses on moisture related respiratory hazards (in this case HDM and fungal growth). In a most basic manner, figure 1 shows the postulated pathways between ventilation and relevant moisture related respiratory problems (note that this diagram only shows a small element of the total complex system). Convenient sub-categories of links are also shown. The review will deal with these links in terms of publications which relate to:

- a link between ventilation rates in dwellings and moisture related respiratory hazards

- a link between moisture related respiratory hazards and respiratory problems 
- a direct link between moisture related respiratory health and ventilation rates in buildings

The following three sections examine the evidence currently available in the literature for these links.

Part of the complexity involved in research in this area is that in most cases it is difficult to measure ventilation rates in a meaningful and accurate manner for the number of properties that are required to provide any statistically significant health data. Also, most changes to ventilation rate have occurred at the same time as other changes e.g. other improvements to the building fabric. Frustratingly, it is not easy to infer the ventilation rate of a property from other building factors such as the age of a property or occurrence of draught stripping. In addition, there are theoretical mechanisms which mean that increased air ventilation is not always beneficial to health (e.g. indoor generated pollutants may decrease but externally generated pollutants may increase).

\section{Studies relating to a link between ventilation rates in dwellings and moisture related respiratory hazards}

There are two key moisture related respiratory hazards - house dust mites and mould growth. The following two subsections review the environmental conditions required for house dust mites and mould and the link with ventilation.

\subsection{House Dust Mites}

Although it is generally accepted that HDM thrive in humid environments, there is some debate as to the actual humidity threshold levels. Many studies refer to the sometimes called "Korsgaard limit" (Lowe, 2000) of $7 \mathrm{~g} / \mathrm{kg}$ absolute humidity, below which mites growth is supposedly inhibited. However, it has been pointed out that mites survival is not dependent on absolute humidity (Crowther et al., 2000) and that the "Korsgaard limit" referred to the context of Danish housing, with typical indoor temperatures of $20-22{ }^{\circ} \mathrm{C}$ (Lowe, 2000), therefore corresponding to $45 \%$ relative humidity $(\mathrm{RH})$. Although relative humidity appears more important than temperature in determining the length of mites' survival (Crowther et al, 2000), the Critical Equilibrium Humidity (CEH) - below which mites dehydration occurs - appears to be dependent on temperature as well (Cunningham, 1996; Arlian and Platts-Mills, 2001). In establishing a limit for the psychrometric control of the mite species D. farina Cunningham (1996) suggested that indoor relative humidity should be kept below $40 \%$ at $16^{\circ} \mathrm{C}, 45 \%$ at $21{ }^{\circ} \mathrm{C}$ and $50 \%$ at $26^{\circ} \mathrm{C}$. On the other hand, Raw (2001) states that RH at $35-40 \%$ in winter, although difficult to achieve in the UK, should be adequate to prevent mite proliferation. Temperature is also an important factor for the egg to adult time span.

It is important to note that HDM survival is not only dependent upon microclimatic hygrothermal conditions but also upon the length of time for which such hygrothermal conditions occur. For example, some studies suggest that adult mites die of dehydration in 5 to 11 days, depending on temperature $\left(25^{\circ} \mathrm{C}\right.$ $34{ }^{\circ} \mathrm{C}$ ) when continuously exposed to RHs of $40 \%$ or $50 \%$ (Arlian and Platts-Mills, 2001). It should also be pointed out that mites are able to move to areas where more favourable environmental conditions occur. Furthermore, some differences have been found between laboratory and 'wild' HDM populations (Crowther et al., 2000). However, most research studies on mites' survival ability have been conducted under steady-state laboratory conditions using cultured populations of HDMs. Although much has been established on HDMs' physiology, further research is required providing a complete knowledge on wild mites' survival rates at various hygrothemal conditions in a transient state.

Sundell et al. (1995) surveyed thirty singlefamily houses all situated in the same area of Stockholm. They found that elevated concentrations of HDM allergen in mattress and floor dust were associated with the difference in absolute humidity between indoor and outdoor air, as well as with low air-exchange-rates of the home, especially the bedroom. In particular, the mean air-exchange-rates of the low infestation group of houses were 0.3 and $0.9 \mathrm{ach}^{-1}$ for the whole house and the bedroom respectively, while in the high infestation group the corresponding mean values were 0.2 and 0.2 $\mathrm{ach}^{-1}$ respectively. Sundell et al. concluded that in regions with a cold winter climate there is a correlation between infiltration and mite 
infestation, but air-flow rates related to number of people in the home appears a stronger indicator of HDM infestation than air-flow rates related to home volumes.

Several studies have been carried out where mechanical ventilation with heat recovery (MVHR) and/or dehumidifiers were utilised in order to reduce relative indoor humidity levels in winter and consequently mite concentrations. However, although the use of MVHR appears to have proven quite successful in Scandinavian countries (e.g.: Emenius et al., 1998; Harving et al., 1994), such an approach has caused some conflicting results in the UK. A study (Fletcher et al., 1996) conducted in the North-West of England on 18 houses - 9 with MVHR and 9 control houses - concluded that "the MVHR unit does not reduce indoor humidity to levels capable of retarding mite population growth and decreasing mite allergens in the type of houses predominantly found in the mild and humid climate of the North-West of England" (ibid., p.1051).

In a later study (Niven et al., 1999), an additional central dehumidification modification of the MVHR (MVHRcd) was adopted in order to further assess the viability of the psychrometric control of HDM in the UK. Ten active houses were fitted with adapted MVHRcd units; relative humidity and allergen levels were monitored for 15 months and compared with the correspondent results of 10 control houses. The target temperature and humidity for the bedrooms in the active houses were $45 \% \mathrm{RH}$ or $7 \mathrm{~g} / \mathrm{kg}$ absolute humidity at $21^{\circ} \mathrm{C}$. The researchers concluded that "the MVHRcd system failed to confer a benefit in terms of mite allergen reduction" (ibid., p.756). However, the authors also pointed out that the buildings' airtightness might have compromised the effectiveness of the MVHRcd system. No measurements of air-infiltration were carried out to determine is this was a possible explanantion.

In a study carried out by Berry et al (1996), it was shown that the houses which rarely or never opened windows had higher mean yearly average mite counts taken from the bedroom carpet. This was not observed with counts obtained from the living room carpet, when the degree of opening the living room window was examined.
Several studies report that HDM numbers increased with the severity of the dampness in the property (Adan et al 1988 and Hart and Whitehead 1990). Toma et al (1993) found that ventilation did not influence mite numbers, but Korsgaard (1979) found that there was a tendency for higher numbers of mites in houses where the number of airing hours (opening up windows) was low. Korsgaard (1979) also found that there was no correlation between the temperature and mite counts. However, Irie et al 1990 found a link between increasing mite numbers and increasing indoor temperatures.

Modeling can provide an insight into this issue. As a result of a two-year research project funded by EPSRC in the UK, two models have been developed for the prediction of HDM in houses (Crowther et al., 2002). The model 'BED3' has a steady-state hygrothermal model linked to an empirical population model. For the latter, laboratory measurements were undertaken with populations of HDM kept for three weeks at different combinations of steady $\mathrm{RH}$ and temperature, covering the range of conditions typical of UK dwellings. The more complex model 'Lectus' is a transient, three-dimensional model that simulates all stages of mite development. The population model adopted in Lectus is based on published data for the Dermatophagoides pteronyssinus, the most common mite species in the UK. With regard to the Lectus population model, the authors of the research pointed out that the existing published data are not complete but there was sufficient information, making simple assumptions, to derive curve-fitted equations. The models BED3 and Lectus were used to examine a range of issues, including the effect of ventilation rates on HDM populations. The study concluded that:

- Small reductions in ventilation rate below $0.5 \mathrm{ach}^{-1}$ can have a dramatic impact. Modelling suggests that reducing from 0.5 to $0.4 \mathrm{ach}^{-1}$ can increase the mite population by 100 times. However, an increase to above $0.7 \mathrm{ach}^{-1}$ can also lead to an increase in the mite population in a fuel poor dwelling

- Raising bedroom temperatures from $16^{\circ} \mathrm{C}$ to $18^{\circ} \mathrm{C}$, i.e. without reducing ventilation, can result in a significant (factor of ten) reduction in mite numbers. The increase in bedroom temperatures over the last 50 years, partly as a result of increased central heating and improved insulation, is therefore likely 
to have had beneficial effects. This supports the case for continuing to improve the UK's housing stock.

- Modelling suggests that building occupant density is a key parameter in determining house dust mite populations. Increasing the number of occupants in a dwelling from 4 to 6 can increase the mite population by 10,000 due to the increased moisture production in the property.

The role of indoor temperatures in the correlation between air-leakage and HDM population is also highlighted by Lowe (2000). The author considered the Critical Equilibrium Humidity (CEH) defined by Cunningham (Cunningham, 1996) of $40 \% \mathrm{RH}$ at $16^{\circ} \mathrm{C}$ and $45 \%$ at $21{ }^{\circ} \mathrm{C}$. Modelling based on a typical UK dwelling and Kew weather data showed that at low internal temperatures the "Cunningham limit" is exceeded for most of the winter and increasing the ventilation rate does not improve the situation greatly. At high internal temperatures, problems appear likely to occur only at ventilation rates significantly less than $0.5 \mathrm{ach}^{-1}$. Ridley et al. (2003) also found through modelling that an air-infiltration rate below 0.5 ach leads to an indoor RH greater than $70 \%$ in fuel rich dwellings $\left(0.7 \mathrm{ach}^{-1}\right.$ for fuel poor dwellings). While in fuel rich dwellings the $\mathrm{RH}$ rapidly decreases with an increase in airleakage, in fuel poor dwellings (who cannot afford to maintain always comfortable indoor temperatures) such inverse correlation does not occur.

\subsection{Mould}

Woolliscroft (1997) stated that the high level of condensation and mould in the UK is the consequence of the small size of the dwellings, low temperatures, high absolute humidity of the incoming air, and high occupancy of dwellings. $35 \%$ of dwellings were affected by condensation and $17 \%$ by mould growth. Comparing these results which were based on the English House Condition Survey 1988, with the same survey in 1996, it can be noticed that the incidence of mould growth of any severity has fallen to $14.6 \%$ of the total stock (DETR, 1996). The latest house condition survey published in 2001 omitted the collection of any condensation and mould data (ODPM, 2003).
A study by the UK Building Research Establishment (BRE) (Research project number EP228, 1990) revealed that recently built one bedroom and bedsit homes in the UK had significant condensation problems, which could lead to mould growth and proliferation. This study gave an indication of the factors related to condensation for example ventilation, air movement, heating and insulation. Their study indicated that the factors such as ventilation, air movement, heating and insulation were more important than occupant behaviour and energy consciousness and the most important occupant characteristics were the number and age of occupants (Raw and Fox 1990 in BRE study, Research project number EP228). BRE (Hunter et al 1988 and 1996) carried out biological assessments of houses and their investigation revealed that the most influential factor affecting the fungal counts appeared to be season.

In summary, it would appear that there is general consensus that links do exist between ventilation rates and moisture related respiratory hazards. We will now move on to consider the links between these hazards and possible respiratory problems.

\section{Studies relating to a link between moisture related respiratory hazards and respiratory problems.}

The most commonly perceived health effect arising from exposure to airborne moulds and other microorganisms, for example HDM, is allergy. Allergy-related diseases include asthma, rhinitis, and eczema or the less common diseases of extrinsic allergic alveolitis (hypersensitivity pneumonitis) and allergic bronchopulmonary aspergillosis (Pope et al 1993). Again, this section initially discusses the link between mites and health before moving on to consider mould.

\subsection{House Dust Mites}

HDM allergens are mostly present in their faecal pellets and they can trigger Type I allergic reactions, including asthma. Some studies also suggest that HDM allergens are associated with other health problems such as eczema and perennial allergic rhinitis. The evidence is reviewed by Raw, (Raw, 2001) who reports that "levels of mite allergen in the dust in most UK homes are high enough to cause sensitisation 
and it is possible that most people in the UK are exposed to enough mite allergen to cause asthma if they are susceptible to this disease for genetic or other reasons" (ibid., 2001, p.15). However, the contribution of HDM as a direct cause of asthma, in comparison with many other predisposing and precipitating causes, is not known

Generally, the effects of pollutants on the lung can be categorised as irritation, inflammation, bronchoconstriction and sensitisation. Some of the more potent agents of allergic lung disease are found in indoor environments; such aeroallergens (house dust mite and moulds) have been recognised for many years. Inner city children have the highest prevalence and the highest mortality rates for asthma in the USA (Call et al 1992) and these children also have a high prevalence of dust mite sensitisation (Platts-Mills and Weck, 1989). However, many other factors could also contribute to this relationship

House dust mites, moulds and, less commonly, amoebae can colonise building structures, services, furnishing and finishes (e.g. Singh, 1999). House dust mites, fungi and yeasts are potent sensitizers, and they flourish in an environment of high relative humidity and low ventilation. Fragments of these organisms or their decayed material or their metabolites, becoming airborne, can be inhaled and cause allergic disease.

An important meta analysis of 23 patient-level intervention studies (Goetzsche et al 1998) was derived from 229 reviewed papers. A total of 230 patients, all showing mite sensitivity shown by skin-prick, were divided between intervention cases and non-intervention controls. Interventions were: 6 using chemical methods, 13 physical methods and 4 combination. No statistical difference was found in symptom responses between intervention and controls. The authors consider the sample size of strong statistical power and so the "most likely explanation' given is either insufficient reduction in house mite levels or other allergens coexisting. In a dissenting editorial, Strachan (1998) suggested that sub-group analysis could still reveal clinically useful interventions with larger studies.

\subsection{Mould}

Now turning to mould in more detail, a number of studies have shown that mould growth in damp housing was associated with childhood respiratory illness; wheezing and asthma ( $\mathrm{Su}$ et al 1990; Flannigan et al 1990; Dales et al 1990; White 1990; Spengler et al 1993; Husman et al 1993). None of these studies was in a peerreview health journal, and do not necessarily demonstrate a causal relationship

The effect of damp and mould in the home on respiratory health was reviewed by Peat et. al. (1998). The reviewer suggested that houses need to be specifically designed for primary prevention of respiratory problems associated with indoor allergen proliferation rather than using post hoc procedures to improve indoor climate and reduce allergen load as a secondary or tertiary preventive strategy. It was strongly emphasised that studies with large sample sizes were needed to measure whether intermittent peak exposures or low cumulative exposures to indoor allergen pose a clinically important risk.

Mould in damp buildings has recently emerged as an indoor environmental hazard of some concern (Lange et al 1993, Singh 1994a and Rylander 2003), although the issue has existed for centuries (Rautuiala et al 1998). A large volume of literature is appearing in journals particularly related to characteristics, distribution, public health, exposure, and health relationships for microbes, including fungi, and the indoor environment (Kalliokoski 2003, Lugauskas et al 2003, Adeeb and Shooter 2003, Sarca et al 2002, Menetrez et al 2002, Menetrez and Forde 2002, Kemp et al 2002a, Kemp et al 2002b and Mussalo-Rauhamaa et al 2003).

There are more than 100,000 species of fungi, and the genera and species possibly linked to human disease involve a wide array of both common and rare moulds. Fungi produce large numbers of spores and when these spores are liberated from infected buildings to the indoor air, they can be regarded as organic dust. These spores can, like other types of dust, sediment on surfaces or can be inhaled by occupants and deposited on the mucosal surface of the upper airways and in the eyes.

Microorganisms and their metabolites may cause a range of respiratory symptoms, 
depending upon the species, the exposure and the immune status of the subject (Singh, 1994a; Singh 1994b; Lacey, 1994; Comtois and Garcia, 1994).

Garret et al (1998) reported that no significant association between total viable mould concentrations and health outcomes was seen despite significant associations with specific genera. Reporting on the findings of the PEACE study, Andriessen et al (1998) concluded that Peak Flow (PEF) variability in atopic children was associated with (but not necessarily caused by) reported moulds in the home.

A few governmental agencies have published guidelines on mould assessment and remediation but most are very general in nature (Minnesota Department of Health. 2001and New York City Department of Health 2000 and Rao et al 1996). Some guidelines focus on toxogenic moulds, including Stachybotrys chartarum, which have been reported in association with health conditions including acute pulmonary haemorrhage (Chapman 2003).

It is helpful to conclude this section of the review with the findings of a recent report (Raw et al, 2001). This study placed HDM in the highest level risk group with regard to health and safety hazards in homes. Fungal growth was placed in the second highest level risk group. In this study, hazards were placed in rank order, from the perspective of deciding whether preventative action was needed. It appears that the actual health risk from mould in buildings has yet to be quantified e.g. Chapman et al (2003) and Bornehag et al (2004). While repeated exposure to large amount of fungal propagules risks the development of specific allergic reactions, there is no adequate evidence of serious health hazards caused by so-called 'toxic' moulds.

In summary, there appears to be general consensus that a link exists between HDM and mould (i.e. respiratory hazards) and respiratory problems Having previously indicated that there is also general consensus that links do exist between ventilation rates and these respiratory hazards we now conclude by exploring what evidence exists to support a direct link between ventilation rates and respiratory problems.

\section{Studies relating to a direct link between moisture related respiratory health and ventilation rates}

The EUROVEN group recently reviewed the scientific literature relating to the effects of ventilation on health, comfort and productivity in non-industrial environments (Wargocki et al 2002). The study concluded that there was a strong association between ventilation and health. Studies judged conclusive implied that low ventilation rates in homes may be one of the factors exacerbating allergies due to the increased rate of infestation of HDM. The study also noted however, that more information is required on links between ventilation rates and health in homes.

A recent study (Emenius et al 2004) was undertaken to examine the impact of building characteristics and indoor air quality on recurrent wheezing in infants. The study found that whilst building-related exposures appear to have a major impact on children's health, this was not primarily explained by differences in ventilation systems, air change rate or HDM infestation.

In some UK studies the adoption of MVHR appeared successful for HDM control (Howieson et al., 2002; Htut et al., 1996; and McIntyre, 1992). However, not all of the studies measured ventilation rates nor the clinical efficacy of the remedial measures.

Howieson et al. $(2002 ; 2003)$ examined the effect of a number of remedial measures (including MVHR, steam cleaning, new bedding) on 54 asthmatic subjects in North Lanarkshire. The study concluded that lung function measurements and health questionnaire data confirmed a significant improvement in the active group compared with the control group. However, the study presented a number of confounding variables. For example, no pressure tests were carried out. In addition, no skin prick tests were undertaken and consequently the project could not differentiate between the health effects influenced by a reduction in HDM allergen levels and/or the overall improvement on indoor air quality produced by greater ventilation rates.

In another UK research project adopting MVHR, twenty houses in the Southampton area were fitted with MVHR and a further 20 houses 
acted as controls (Stephen et al., 1997; Warner et al, 2000). As air-infiltration was also measured, the effect of air-leakage on indoor humidity was explored using linear regression. It emerged that the houses group with MVHR showed a significant effect of leakiness with leaky houses having lower humidity. In the control houses, however, it appears that humidity was not affected by the houses' leakiness. However, the independent analysis of the two groups does not show that the two results are statistically different from each other. As regards the effect of MVHR on allergen concentration, Warner et al (2000) noted that there was evidence for a beneficial effect of MVHR on Der p1 levels. However, the reduction in allergen levels did not result in a significant clinical improvement - the power of this study was low to detect clinical changes. "The likelihood of being able to show a change in clinical symptoms could be improved by performing a larger study and ventilating more areas of the houses, possibly with the inclusion of active dehumidification within the systems." (ibid).

Many studies do not attempt to investigate the links between ventilation and health but rather between dampness and health. Ventilation and damp can be closely related and so such studies are reported here. There is however, a lack of clarity in the literature as to the definition of a 'damp' building. For example, high absolute humidity, high relative humidity, high moisture content of elements of the fabric and the occurrence of mould are all possible indicators. This definition is critically important because whereas, for example, the absolute humidity will always tend to drop with increased ventilation (unless the external absolute humidity is higher), relative humidity is a function of both temperature and the moisture content of the air and so increased ventilation can, under some circumstances, increase relative humidity.

A recent report (ISBE, 2003) concluded that extensive knowledge exists on the influence of humid environments to human health. Health problems in damp and humid buildings were first described by Leeuwen (1924) and these problems related to buildings have received increased attention over the last few decades. In the last two decades several large studies in the UK, USA, Scandinavian Countries and the Netherlands strengthened confidence in the relationship between indoor environmental humid conditions and an increase in asthma, impaired respiratory function, general respiratory symptoms and respiratory infection among children (Brunekreef et al 1993; Dales et al 1991; Cuijpers et al 1995; Li and Hsu 1996 and Rylander 2003)).

A recent review of the literature on dampness and HDM exposure in buildings and health effects (Bornehag et al 2004) concluded that dampness is a risk factor for health in domestic environments but that the literature is not conclusive in respect of causative agents. The strong need for more multidisciplinary studies was noted.

A recent study (Hagerhed et. al., 2002) reported that dampness (inferred from visible signs of mould and condensation, coupled with the perception of indoor air quality e.g. 'stuffy air') is more common in older buildings and buildings with natural ventilation. Bornehag (2002) summarised 15 different studies on dampness and health concluding that in 13 studies a positive association was found between dampness and health effects namely asthma and wheezing.

A study conducted in Scotland (Williamson, 1997) showed that asthmatic patients attending a hospital asthma clinic were two to three times more likely to live in a dwelling with evidence of dampness (inferred from fabric moisture content and severity of mould) than an age and sex matched random sample of the general population living in the same area of the city of Glasgow.

Further confirmation of the significant influence of house dampness and mould on health status is reported in numerous, mainly medical, reports and journals (Garrett et. al., 1998; Andriessen, et. al., 1998; Zock, et. al., 2002; Zureik, et. al., 2002).

As noted earlier, some of the studies reported here do not deal directly with ventilation - rather 'damp' housing. The two are related but it is clear that the number of studies which have attempted to link ventilation rates directly to respiratory problems are scarce.

It may be helpful to conclude this section with the findings of the National Academy of Sciences, USA. The results of workshops in 1999 (Committee, 2000) reported 'existing data 
are inadequate for conclusions regarding the association between ventilation rates or ventilation system microbiological contamination and either the exacerbation of asthma symptoms or asthma development.' 'Airtight building envelopes and low rates of ventilation have been cited as factors that may contribute to asthma incidence or symptoms or may explain recent increases in asthma; however, very few relevant data are available ... ....measurements of ventilation rates should be included, when possible, in future asthma casecontrol studies or cross-sectional surveys.'

\section{Discussion}

The literature review highlights the limited research that has been undertaken to demonstrate a direct relationship between domestic ventilation and health. The medical and building science literatures include many publications addressing ventilation and health in offices, but few domestic housing studies. There have been studies by occupational health services to support the growing white-collar workforce but because private housing is not regulated by health and safety legislation there are fewer relevant studies. Also, it is relatively difficult to measure ventilation in housing: current techniques can only be undertaken on a small number of dwellings at a time. Yet, health studies generally require large occupant samples.

Health effects of pollutants can be studied in three ways - medicine, toxicology and epidemiology. Typically, the first is of concern in relation to an individual person. The person has unexpected symptoms, and explanations for these are sought in the surrounding environment. If a particular aspect of the environment is suspected, then two further directions are possible: toxicological studies will test the possible agent in laboratory settings (for example, effects on tissue cultures or mice); epidemiological studies will compare the frequency of the disease in people exposed to the pollutant with people not exposed.

This approach has served industrial medicine well, and has identified potential hazards of particular working environments, for example dyes in the chemical industry causing bladder cancer and asbestos in the construction industry causing lung mesothelioma. But assessing the effects of pollutants in the home is more complicated. People living at home have a varied environmental exposure (living in different rooms, working with different materials, periods of time in and out of the house) and these are not usually recorded before the onset of symptoms. The levels of exposure are probably below industrial levels, and health records not so accessible. In general, whereas occupational health services assess the health of workers in the workplace, general medical services rarely see people in their homes except for nursing and care services.

In the industrial examples given above, the diseases identified were relatively unusual. On the other hand, respiratory symptoms that may be attributed to housing are widely prevalent. Coughs and colds affect most people every year. Moderate or severe symptoms can arise from infections (bronchitis and pneumonia) and 'asthma', (a state of narrowing of respiratory airways). The United Kingdom has the largest proportion of people in Europe who believe they have asthma - one in three of the population by current surveys. (Whether the country comparisons are accurate is another question: the rapid growth in self-diagnosis of asthma suggests a possible re-allocation of other respiratory complaints \{coughs and colds $\}$ ). Respiratory symptoms are common; and so also are the various factors suggested to cause them. To focus on asthma again, the range of possible 'causes' include respiratory infections, chemical vapours in the air, ingested chemicals, dustborne particles, temperature changes, smoking, exercise and psychological reactions. Asthma symptoms occur because of inflammation of the respiratory tract. 'Allergy' is only one of several pathways for the body to create the inflammation, and people who are 'allergic' don't necessarily have that as the cause of specific asthma symptoms - which may be the result of a simple viral infection (cold, cough) or increased obesity making exercise more difficult.

Good studies relating home air to respiratory symptoms are difficult to achieve. Symptoms are common and difficult to standardise, while exposures are equally hard to record. Typically, studies have tried to focus on asthma as a disease, since it occurs in children and there appear to be a wide variety of triggers. Three sorts of epidemiological studies can be used: 
Cross-sectional studies are most common.

These surveys record existing exposures in housing and existing levels of disease, and look for statistical associations between the two. The weakness in these studies is 'confounding' - that is, several factors may be identified statistically, but another factor (perhaps unrecorded) may be having a greater real effect. Other criteria, including strength of association, biological plausibility and specificity of the effect should be considered in evaluating the results.

Case-control studies compare people with symptoms against people without symptoms, and look for different levels of exposure. These studies can look at past exposure, and therefore show whether exposure happened before disease - which cross-sectional studies cannot. Nevertheless, it is necessary to collect information on all possible causes, and still the case-control design does not exclude confounding factors.

Longitudinal population studies have the strongest scientific design. They follow a cohort of people forwards in time. They measure the exposure before onset of the disease, and therefore help avoid confounding factors. However, they have to be large, since only a proportion of people tracked over time will develop the symptoms. This in turn means measuring ventilation over a large number of properties which is very expensive.

In the field of domestic ventilation and health so far, only two sides of the equation have been assessed in detail: there have been studies of the effects of ventilation on air characteristics, such as dust mites, mould spores, carbon monoxide; and there have been studies showing how these factors are associated with respiratory symptoms and diseases. But, in contrast to office studies, there have been relatively few direct studies of domestic ventilation and diseases.

It may be reasonable to accept the separation of the 'technical' studies of ventilation from the 'medical' studies of air and disease. Thus, if ventilation reduces pollutants, then potential harm may be reduced. But it would be welcome to know whether there was a real effect because the implications of ventilation are not negligible. Energy efficiency seeks to maintain indoor temperatures while reducing heat loss. 'Tight' buildings have reduced levels of natural ventilation; but they may have increased pollutants, for example, high concentrations of domestic chemicals (e.g. cleaning materials), cooking gases (carbon monoxide) or house dust mites (through higher humidity). These in turn are believed to have respiratory symptom consequences, but the link to levels of ventilation is unknown - making it difficult to give appropriate guidance.

Two other points are relevant for the discussion. First, the concept of 'attributable risk'; this suggests how much a factor contributes to a disease (attributable fraction) or how many people may be affected (population attributable fraction). While the attributable fraction may be low - say only one in twenty cases, if the disease is widespread then the population effect can be quite large in number of cases. (Take, for example, the view that current levels of external air pollution are causing more than 10,000 premature deaths in Britain each year.) A scientific study of ventilation would wish to make some numerical estimate of the health effects.

Second, it is probable that there is a threshold level for some pollutants. Equally, it is possible for human bodies to excrete or detoxify some chemicals. We do not have adequate knowledge of thresholds and should not assume that only a perfectly 'clean' environment is healthy. Ventilation itself is not a health hazard. However there is considerable theoretical evidence to support the hypothesis that ventilation rate around the levels controlled by the Building Regulations can have a health effect. The pathways are summarised in Figure 1. However, this diagram hides the complexity in trying to identify if a real link exists. Ventilation may impact on hazards and then respiratory problems which are not only affected by spores and faeces but also by other hazards. This is made more complex by the real difficulties in monitoring ventilation, hazards and respiratory problems in one study. It is these difficulties in monitoring that may, in part, explain the often conflicting results from different studies. Being able to monitor ventilation, HDM populations, mould growth and respiratory problems is key to determining a link. The difficulties in monitoring respiratory problems are discussed above but an important issue also relates to most studies relying on self reporting rather than any medical diagnosis.

Measuring the actual hazards (mould and house dust mites) is also problematic. Although the 
English House Condition Survey has developed a method to rate the severity of mould growth by surveyors, many studies simply rely on the occurrence of any mould, condensation or damp - terms which can have a wide range of different interpretations. It is possible for example to hypothesise a scenario where the occurrence of condensation could reduce mould and house dust mites. For example, condensation on single glazing may be a useful stimulus for occupants to increase occupant controlled ventilation which in turn would lead to less mould and HDM. The advantage of monitoring mould is that it is at least visible and so self reporting is possible. However, there is the complexity that mould may be evident due to a previous problem which no longer exists if it has not been cleaned up. In the case of HDM, these are not visible and monitoring is very difficult. HDM populations also vary seasonally due to the change in outside vapour pressure. Sampling is very dependent on the methods used, e.g. vacuum cleaning area of the building, since mites are invisible there may be a colony of mites which happen to have the correct micro-environment in a location which has not been sampled. Also it is not the mites themselves that cause the respiratory problems but their faeces which have a long life and can be present even if the colony has been eradicated.

As noted earlier, domestic ventilation is also very difficult to measure on the scales required and no reliable methods of inferring domestic ventilation rates have been developed. The most commonly measured parameter to infer ventilation rates is pressure testing. However, pressure testing only reveals something about the background air infiltration and nothing about the occupant controlled ventilation.

\section{Conclusions}

A key change in this field in recent years has been a move from extrapolating from laboratory studies of air pollution causing respiratory symptoms to the use of a limited number of epidemiological studies of the real world for long-term effects.

An extensive body of literature exists which attempts to investigate relationships between ventilation and indoor air quality. There is general consensus that a link exists between ventilation rates in dwellings and respiratory hazards (for example HDM). There is also general consensus that a link exists between these respiratory hazards and respiratory problems. For relevant moisture related respiratory hazards (HDM and fungal growth), the literature offers some advice on the minimum required ventilation rates to prevent unacceptable hazard and the consequent respiratory health risks.

Of particular interest though, it appears that most existing data are inadequate for conclusions to be drawn regarding the direct association between ventilation rates and respiratory problems. It is noted that there are many real difficulties in attempting to establish such a relationship and further work may be required to achieve this

\section{Acknowledgements}

The larger studies, of which this literature review forms part, were funded by the UK Government's Building Regulations Research Programme.

\section{References}

Adan, O., Schober, G., Kniest, F. and Vorenkamp, J. (1988) "Modification of indoor humidity conditions: an allergological sanitation method for the indoor environment", Revue Francaise D'Allergologie et D'Immunologie Clinique, Vol. 28, pp. 147-151.

Adeeb, F., Shooter, D.(2003) "Emission and evolution of air-borne microflora in slaughter houses", Indoor-Built Environ, Vol. 12, pp. 179184.

Andriessen, J.W., Brunekreef, B., Roemer, W. (1998) "Home dampness and respiratory health status in European children", Clinical and Experimental Allergy, Vol. 28, pp. 1191-1200.

Arlian, L.G., Platts-Mills, T.A. (2001) "The biology of dust mites and the remediation of mite allergens in allergic disease", Journal of Allergy Clinical Immunology, Vol. 107 (3 Suppl.), pp. S406-13. 
Berry, R.W., Brown, V.M., Coward, S.K.D., Crump, D.R., Gavin, M., Grimes, C.P., Higham, D.F., Hull, A.V., Hunter, C.A., Jeffery, I.G., Lea, R.G., Llewellyn, J.W. and Raw, G.J. (1996) "Indoor air quality in homes: part 1. The Building Research Establishment Indoor Environment Study", London, Construction Research Communications.

Bornehag, CG, Sundell, J, Bonini, S, Custovic A, Malmberg P, Matricardi, P, Skerfving S, Sigsgaard, T \& Verhoeff, A. (2004) Dampness in buildings as a risk factor for health effects, EUROEXPO. A multidisciplinary review of the literature (1998-2000) on dampness and mite exposure in buildings and health effects Indoor Air Vol. 14(4) pp. 243 257.

Bornehag, C.G. and Sundell, J. (2002) "Dampness in buildings as a risk factor for health effects", in: Proceedings: Indoor Air 2002. $9^{\text {th }}$ International Conference on Indoor Air Quality and Climate, Monterey, Indoor Air 2002.

Brunekreef, B., Verhoeff, R.T., van Strien and van Wijnen. (1993) "The role of sensitisation to dust mites and moulds in explaining the relationship between home dampness and childhood respiratory symptoms", in:

Proceedings of Indoor Air 93: 6th international conference on indoor air and climate, Vol 1, pp 153-158.

Building Research Establishment, (1990), "Research project number EP228", Garston, BRE.

Call, R.S., Smith, F.T., Morris, E. Chapman, M.D., Plat-Mills, T.A.E. (1992) "Risk factor for asthma in the inner city children", The journal of paediatrics, Vol 121, pp. 862-866.

Chapman, J.A., Terr, A.I., Jacobsn R.L., Charlesworth, E.N., Bandana, E.J. (2003)

"Toxic mould: phantom risk vs. science", Ann Allergy, Asthma and Immuno., Vol. 91, pp. 222232.

Committee on the Assessment of Asthma and Indoor Air. (2000) "Clearing the Air", Washington, National Academy Press.
Comtois, P. and Garcia, B.E. (1994) "Indoor mycology the Northern American Experience", in: Singh, J (Edited by), Building Mycology, Management of Health and Decay in buildings, London, E \& FN Spon, pp. 260-280.

Crowther, D., Horwood, J., Baker, N., Thomson, D., Pretlove, S., Ridley, I., Oreszczyn, T., (2000), "House Dust Mites and the Built Environment: a Literature Review", available online at:

www.arct.cam.ac.uk/research/mite/review.pdf.

Crowther, D., Pretlove, S., Ridley, I., Oreszczyn, T., Wilkinson, T. (2002) "A Hygrothermal Model of House Dust Mite Response to Environmental Conditions in Dwellings Summary Report", available online at: http://www.arct.cam.ac.uk/research/mite/four.pd f.

Cuijpers, C.E.J., Swaen, G.M.H., Wessling, G., Sturmans, F., Wouters, E.F.M. (1995) “Adverse effects of the indoor environment on respiratory health in primary school children", Environ Res, Vol. 68, pp. 11-23.

Cunningham, M. J. (1996) "Controlling Dust Mites Psychrometrically - a Review for Building Scientists and Engineers", Indoor Air, Vol. 6, pp. 249-258.

Dales, R., Zwanenburg, H. and Burnett, R. (1990) "The Canadian air quality health survey: Influence of home dampness and moulds on respiratory health", in: Proceeding of Indoor air '90. 5th international conference on Indoor air quality and climate, Ottawa, Indoor Air 90, Vol. 1, pp 145-147.

Department of Environment, Transport and Regions, (1996) "English House Condition Survey 1996", London, DETR.

Emenius G., Svartengren M., Korsgaard J., Nordvall L., Pershagen G. and Wickman M. (2004) Building characteristics, indoor air quality and recurrent wheezing in very young children (BAMSE), Idoor Air Vol. 14(1) pp. 34 -42 .

Emenius, G., Egmar, A., Wickan, M. (1998) "Mechanical ventilation protects one-storey single-dwelling houses against increased air humidity, domestic mite allergens and indoor pollutants in a cold climatic region", Clinical 
and Experimental Allergy, Vol. 28(11), pp. 1389-96.

Flannigan, B., MaCabee, E.M., McGarry, F. and Strachan, D.P. (1990) "Wheeze in children: An investigation of air spora in the home", in: Indoor air '90. 5th international conference on Indoor air quality and climate, Ottawa, Indoor Air 90, Vol. 2 pp. 27-32.

Fletcher, A.M., Pickering, C.A., Custovic, A., Simpson, J., Kennaugh, J., Woodcock, A. (1996), "Reduction in humidity as a method of controlling mites and mite allergens: the use of mechanical ventilation in British domestic dwellings", Clinical and Experimental Allergy, Vol. 26(9), pp.1051-6.

Garrett, M.H., Rayment, P.R., Hooper, M.A., Abramson, M.J., Hooper, B.M. (1998) "Indoor airborne fungal spores, house dampness and associations with environmental factors and respiratory health in children", Clinical and Experimental Allergy, Vol. 28, pp. 459-467.

Gotzsche, P.C., Hammrquist, C., Burr, M. (1998) "House dust mite control measures in the management of asthma: meta-analysis", British Medical Journal, Vol. 317, pp.1105-1110.

Hagerhed, L., Bornehag, C.G., Sundell J. (2002) "Dampness in buildings and health. Building characteristics as predictors for dampness in 8681 Swedish dwellings", in: Proceedings: Indoor Air 2002. $9^{\text {th }}$ International Conference on Indoor Air Quality and Climate, Monterey, Indoor Air 2002.

Hart, B.J. and Whitehead, L. (1990) "Ecology of house dust mite in Oxfordshire", Clinical and Experimental Allergy, Vol. 20, pp. 203-209.

Harving, H., Korsgaard, J., Dahl, R. (1994) "Clinical efficacy of reduction in house-dust mite exposure in specially designed, mechanically ventilated "healthy" homes", Allergy, Vol. 49(10), pp.866-70.

Howieson, S.G., Lawson, A., McSharry, C., Morris, G., McKenzie, E. (2002) "1B2O5 Indoor Air Quality, Dust Mite Allergens And Asthma", in: Proceedings Indoor Air 2002. $9^{\text {th }}$ International Conference on Indoor Air Quality and Climate, Monterey, Indoor Air 2002, pp.113-118.
Howieson, S.G., Lawson, A., McSharry, C., Morris, G., McKenzie, E., Jackson, J. (2003) "Domestic ventilation rates, indoor humidity and dust mite allergens - Are our homes causing the asthma pandemic", Building Services

Engineering, Research and Technology Journal, Vol. 24, No. 3, pp.137-147.

Htut, T., Burgess, I.F., Maunder, J.W., Basham, E. (1996) "A pilot study on the effect of one room mechanical ventilation with heat recovery (MVHR) units on house dust mite populations and Der $\mathrm{p} 1$ levels in laboratory simulated bedrooms and on ambient conditions in an occupied bedroom in Cambridge, UK", International Journal of Environmental Health Research, Vol. 6, pp.301-313.

Hunter, C.A., Grant C., Flannigan B. and Bravery A.F. (1988) "Mould in buildings: the air spora of domestic buildings", International Biodeterioration, Vol. 24, pp. 81-101.

Hunter, C.A., Hull A.V., Higham, D.F., Grimes, C.P. and Lea, R.G. (1996) "Fungi and bacteria" in: Berry, R. W., Brown, V. M., Coward, S. K.D., Crump, D. R., Gavin, M., Grimes, C. P., Higham, D. F., Hull, A. V., Hunter, C. A., Jeffery, I. G., Lea, R. G., Llewellyn, J. W. and Raw, G. J., (1996), BRE Report 299. Indoor air quality in homes: part 1, Garston, BRE; pp 97115.

Husman, T., Koskinen O., Hyvarinen A., Reponen T., Ruuskanen J. and Nevalainen A. (1993) "Respiratory symptoms and infections among residents in dwellings with moisture problem or mould growth", in: Proceedings of indoor air 93; 6th international conference on indoor air quality and climate, Vol 1, pp171174.

Irie, T., Hasegawa, Y. and Yoshikawa, M. (1990) "Measurement of living mites in private wooden dwellings, Japan", in: Proceedings International Conference on Indoor Air Quality and Climate, Ottawa, Vol. 2, pp 61-66.

ISBE (International Society of the Built Environment), (2003) "Workgroup Report", Indoor and Built Environment, Vol. 12(4), pp. 259-264.

Kalliokoski, P. (2003) "Risks caused by airborne microbes in hospitals - source control is 
important", Indoor-Built Environ.; Vol. 12, pp. 41-46.

Kemp, P.C., Neumeister-Kemp H.G., Kock, C., Lysek, G., Murray, F. (2002a) "Determining the Growth and Vitality of Micro-Organisms in Carpets and Mattresses in Non-Problem Dwellings by Measuring CO2 Released during Respiration", Indoor-Built Environ, Vol.11, pp.214-220.

Kemp, P.C., Neumeister-Kemp H.G., Murray, F., Lysek, G. (2002b) "Airborne Fungi in NonProblem Buildings in a Southern-Hemisphere Mediterranean Climate: Preliminary Study of Natural and Mechanical Ventilation", IndoorBuilt Environ., Vol. 11, pp. 44-53.

Korsgaard, J. (1979) "The effect of indoor environment on house dust mite", in: $\mathrm{P} O$ Fanger and O Valbjorn, (Edited by), Indoor Climate, Copenhagen, Danish Building Research Institute, pp 187-199.

Lacey, J. (1994) "Indoor aerobiology and health", in: Singh, J., (Edited by), Building Mycology, Management of Health and Decay in buildings, London, E \& FN Spon, pp. 77-130.

Lange, J.H., Grad, J.W., Lange, P.A., Thomulka, K.W., Dunmyre, G., Lee, R.J., Richardson, C.F., and Blumershire, R.V.H. (1993) "Asbestos abatement of ceiling panels and mould growth in a public school building after water damage: a case study", Fresenius Environ Bulletin, Vol. 2, pp. 13-18.

Leeuwen, W.S. (1924) "Bronchial asthma in relation to climate", Proc Roy Soc Med, pp. 1719.

Li, C.S. and Hsu, L.Y. (1996) "Home dampness and childhood respiratory symptoms in a subtropical climate", Arch Environ Health, Vol. 51, pp. 42-46.

Lowe, R. (2000) "Psychrometric control of Dust mites in UK Housing", Building Services Engineering Research and Technology, Vol. 21, No. 4, pp.274-276.

Lugauskas, A., Krikstapois, A., Seskauskas, V. (2003) "Species of conditionally pathogenic Micromycetes in the air of dwelling and occupational premises", Indoor-Built Environ, Vol.12, pp. 167-178.
McIntyre, D.A. (1992) "The control of house dust mites by ventilation: a pilot study", Proc. $13^{\text {th }}$ AIVC Conf., Nice, AIVC, pp.497-507.

Menetrez, M.Y., Forde K.K., DeJesus V.R. (2002) "Testing Antimicrobial Efficacy on Porous Materials", Indoor-Built Environ., Vol.11, pp. 202-207.

Menetrez, M.Y., Foarde, K.K. (2002)

"Microbial Volatile Organic Compound Emission Rates and Exposure Model", Indoor-

Built Environ., Vol. 11, pp. 208-213.

Minnesota Department of Health (2001)

"Recommended best practices for mould investigations in Minnesota schools", Environmental Health Division, Indoor Air Unit, St. Paul, Mn 55164.

Mussalo-Rauhamaa, H., Suomalainen, H., Helin, T., Elg, P., Orpana, A. (2003) "Bronchoalveolar lavage findings from persons exposed to moulds in water-damaged houses", Indoor-Built Environment, Vol. 12, pp. 237-237.

New York City Department of Health (2000) "Guidelines on assessment and remediation of fungi in indoor environments", New York, Bureau of Environmental and Occupational Disease Epidemiology.

Niven, R., Fletcher, A.M., Pickering, A.C., Custovic, A., Sivour, J.B., Preece, A.R., Oldham, L.A., Francis, H.C. (1999)

"Attempting to control mite allergens with mechanical ventilation and dehumidification in British houses", Journal of Allergy Clinical Immunology, Vol. 103 (5 Pt 1), pp. 756-62.

Office of the Deputy Prime Minister (ODPM), (2003), "English House Condition Survey 2001”, ODPM, London.

Peat, J.K., Dickerson, J., Li, J. (1998) "Effects of damp and mould in the home on respiratory health: a review of the literature", Allergy, Vol. 53, pp. 120-128.

Platts-Mills, T.A.E. and De Weck, A.L. (1989) "Dust mite allergens and asthma: A world wide problem", J Allergy Clin Immunol., Vol. 83, pp. 416-27. 
Pope, A.M., Patterson, R. and Burge, H. (Edited by) (1993) "Indoor allergens: assessing and controlling adverse health effects", Washington, National Academy Press.

Rao, C.Y., Burge, H.A., Chang, J. (1996)

"Review of quantitative standards and guidelines for fungi in indoor air", $J$ Waste Manag Assoc., Vol. 46, pp. 899-908.

Rautuiala, S., Reponen, T., Nevalainen, A., Husman, T., Kalliokoski, P. (1998) "Control of exposure to airborne viable microorganisms during remediation of mouldy buildings: report of three case studies", Am J Ind Hyg., Vol. 59, pp. 455-460.

Raw, G.H. and Fox, T.A. (1990) "Condensation heating and ventilation in small homes", in: $C I B$ Conference. Energy moisture and climate, Rotterdam, CIB.

Raw, G.J., Aizlewood, C.E. and Hamilton, M. R. (2001) "Building Regulation, Health and Safety”, Garston, BRE.

Ridley, I., Fox, J., Oreszczyn, T., Houng, S.H. (2003) "The impact of replacement windows on air infiltration and indoor air quality in dwellings", The International Journal of Ventilation, Vol. 1, No. 3, pp. 209-218.

Rylander, R. (2003) "Humid building - the problem", Indoor and Built Environment., Vol. 12, pp. 211-213.

Sarca, S, Asan, A, Otkun, MT, Ture, M. (2002) "Monitoring Indoor Airborne Fungi and Bacteria in the Different Areas of Trakya University Hospital, Edirne, Turkey", IndoorBuilt Environ., Vol. 11, pp. 285-292.

Singh, J. (1994a) "Building Mycology Management of Health and Decay in buildings", London, E \& FN Spon.

Singh, J. (1994b) "Allergy Problem in Buildings", Lancaster, Quay Publishing. No.1, pp. 22-34.

Singh, J. (1999) Sick Building Syndrome, Facilities Management, Health and Safety, November issue, pp. 12-15.

Spengler, J., Neas, L., Nakai, S., Dockery, D., Speizer, F., Ware, J., and Raizenne, M. (1993)
"Respiratory symptoms and housing characteristics", in: Proceedings of indoor air 93; 6th international conference on indoor air quality and climate, Vol 1, pp. 165-170.

Stephen, F. R., McIntyre, D. A., Lane, A., Raw, G.J., Wiech, C.R., Frederick, J. (1997)

"Ventilation and House Air Tightness: Effect on Indoor Temperature and Humidity in Southampton, UK", BSERT (Building Services Engineering Research Technology Journal), Vol.18, No.3, pp.141-147.

Strachan, D.P (1998) "House dust mite allergen avoidance in asthma. Benefits unproved but not yet excluded”, British Medical Journal, Vol. 317, pp.1096-1097.

Su, H.L., Spengler, J.D., and Burge, H.A. (1990) "Examination of microbiological concentration and examination with childhood respiratory health", in: Proceedings of indoor air 90; 5th Indoor international conference on indoor air and climate, Ottawa, Indoor Air 90, Vol. 2, pp. 21-26.

Sundell, J., Wickman, M., Pershagen, G., Nordvall, S.L. (1995) "Ventilation in homes infested by house-dust mites", Allergy, Vol. 50, No. 2, pp.106-12.

Toma, T., Miyagi, I., Kishimoto, M., Nagama, T., and Tamanaha, I. (1993) "Fauna and seasonal appearances of mites in house dusts collected from the residences including asthmatic children in Okinawa Prefecture, Ryukyu Archipelago", Japanese Journal of Sanitary Zoology, Vol. 44, pp. 223-225.

Wargocki, P., Sundell, J., Bischof, W. (2002) "Ventilation and health in non-industrial indoor environments: report from a European Multidisciplinary Scientific Consensus", Indoor Air; Vol. 12, No. 2, pp. 113-8.

Warner, J., Ferderick, J., Bryant, T., Weich, C., Raw, G., Hunter, C., Stephen, F., McIntyre, D. and Warner, J. (2000) Mechanical ventilation and high efficiency vacuum cleaning: a combined strategy of mite and mite allergen reduction in the control of mite-sensitive asthma, J.Allergy Clin. Immunol., 106(No. 1, Pt 1), $75-82$.

White, J.H. (1990) "Solving moisture and mould problems", in: Proceedings of indoor air 90; 5th 
international conference on indoor air quality and climate, Ottawa, Indoor Air 90, Vol. 4, pp. 589-594.

Williamson, I.J., Martin, C.J., McGill, G., Monie, R.D.H., Fennerty, A.G. (1997) "Damp housing and asthma: a case control study", Thorax, Vol. 52, pp. 229-234.

Woolliscroft, M., (1997), "PH-97-8-3.

Residential Ventilation in the United Kingdom: An Overview", ASHRAE Transactions:

Symposia, Vol. 103, No. 1, Paper Number: PH97-8-3, pp. 706-716.
Zock, J.P., Jarvis, D., Luczynska, C., Sunyer, J., Burney, P. (2002) "Housing characteristics, reported mould exposure, and asthma in the EC respiratory health survey", Journal of Allergy and Clinical Immunology, Vol. 110(2) pp. 285292.

Zureik, M., Neukirch, C., Leynaeret, B., Liard, R., Bousquet, J., Neukirch, F. (2002) "Sensitisation to airborne moulds and severity of asthma: cross sectional study from EC respiratory health survey", $B M J$, Vol. 325 (7361) pp. 411-414. 